\title{
Análise do armazenamento de milho no Brasil em um mercado de economia aberta
}

\author{
Vania Di Addario Guimarães 1 \\ Geraldo Sant’Ana de Camargo Barros ${ }^{2}$
}

Resumo: O estudo desenvolve um modelo dinâmico de expectativas racionais para analisar o mercado de milho no Brasil no final da década de 1990, no qual o governo intervém com uma política de subsídio ao produtor, através do Prêmio para Escoamento de Produto (PEP) e considerando ainda o comércio internacional. O modelo é estimado através de programação dinâmica estocástica. Os resultados mostram que a abertura do mercado transfere para o comércio exterior o papel de amortecedor de choques de oferta e demanda internos que, no caso de mercados fechados, é desempenhado pelos estoques entre anos safra. Os resultados sugerem que, dependendo dos valores relativos entre o preço mínimo e o preço de exportação, a política de subsídio pode levar o país à condição de exportador, às custas de gastos crescentes para o governo.

Palavras-chave: Estoques. Política de Preços. Expectativas Racionais.

Classificação JEL: Q11, Aggregate Supply and Demand Analysis; Prices.

\footnotetext{
1 Doutora em Economia Aplicada pela ESALQ/USP, Professora Adjunta do Departamento de Economia Rural e Extensão da Universidade Federal do Paraná. addariov@ agrarias.ufpr.br

2 Professor Titular do Departamento de Economia, Administração e Sociologia Rural da ESALQ/USP. gscbarro@esalq.usp.br
} 
Abstract: A dynamic rational expectation storage models was developed to represent the Brazilian corn market in the late 90's. In theses years the Brazilian agricultural price policy changed from a buffer stock scheme to a producer price subsidy (Prêmio para Escoamento de Produto - PEP) and the Brazilian market was open to international trade. The model was estimated through stochastic dynamic programming.

The results show that with open markets, exports and imports play the role of shocks absorbers, played by storage in closed economies. Results suggest that the producer price subsidy policy may lead the country to be an exporter, depending on the relative values between minimum price and export price at the cost of ever increasing government expenditures.

Key word: Storage. Price Policy. Rational Expectation.

Classificação JEL: Q11, Aggregate Supply and Demand Analysis; Prices.

\section{Introdução}

A formação de estoques entre anos safra de produtos agrícolas pela iniciativa privada é um tema pouco explorado na literatura brasileira e internacional. Em geral, quando a influência dos estoques entre anos safra foi objeto de estudo, o interesse era em avaliar o efeito de estoques governamentais sobre o mercado. As pesquisas fundamentais nesta linha são as de Waugh (1944), Oi (1961), Massel (1969) e podem ser encontradas ainda em Reutlinger (1976), Turnovsky (1974) e outros. Em todos estes casos, o armazenamento privado é ignorado.

Até meados da década de 1990, pouca atenção foi dada aos estoques privados também no Brasil, concentrando-se nos efeitos dos estoques públicos (Lima e Barros, 1996; Barros e Guimarães, 1998). Mas na década de 1990 a política de preços agrícolas no Brasil acompanhou um conjunto de outras mudanças, incluindo a abertura do mercado ao comércio exterior, pela redução ou eliminação das alíquotas de importação. A nova política brasileira de preços agrícolas procura garantir um preço mínimo aos produtores, mas sem que o governo tenha de formar estoques. Os instrumentos desta nova política são o Prêmio para Escoamento de Produto (PEP) e os Contratos de Opção de Venda. No que se 
refere à formação de estoques entre anos safra, o instrumento de maior interesse é o PEP, pois as opções vencem no próprio ano safra e, assim, teriam maior efeito sobre o estoque intra-ano.

O Prêmio para Escoamento de Produto (PEP), lançado em 1996, é um destes novos instrumentos da PGPM e tem por objetivo permitir que a iniciativa privada adquira a produção no período de safra garantindo ao produtor o preço mínimo, subsidiando os produtores (CONAB, 2000). Uma determinada quantidade de lotes de produto (cujos proprietários são identificados) é colocada em leilão com um prêmio máximo que o governo se dispõe a aceitar. Leva o produto aquele comprador que ofertar o menor prêmio, ou seja, o menor subsídio pelo qual ele aceita adquirir o produto. Considerando um ambiente competitivo, o prêmio de arremate dos leilões corresponde à diferença entre o preço mínimo e o preço de equilíbrio de mercado. Assim, o PEP é um subsídio de preço ao produtor rural e afeta, inicialmente, as decisões de produção dos agricultores, mas deve ter influência sobre todo o mercado. Este estudo se concentra em analisar o efeito do subsídio através do PEP para o mercado brasileiro de milho.

Até década de 1980, a teoria do armazenamento não deu a devida atenção a duas características do problema. A primeira é que o armazenamento é um problema econômico dinâmico, pois a decisão no período corrente afeta o(s) período(s) futuro(s). Portanto, a estática comparativa não é o arcabouço teórico adequado para a análise de problemas de formação de estoques, mas sim, a Teoria do Controle. A segunda característica é o fato de que é possível guardar produto de um ano para consumir no futuro, mas não é possível emprestar produto do futuro para consumir no presente, ou seja, o estoque não pode ser negativo e a atividade de armazenar num determinado período pode não ocorrer.

Na década de 1980 estes dois pontos foram devidamente incorporados ao estudo de formação de estoques de produtos agrícolas resgatando o trabalho pioneiro de Gustafson (1958). Sob esta nova visão surgiram diversos estudos como Gardner (1979), Wright \& Williams (1984), Lowry et al. (1987), Glauber et al. (1989), Miranda \& Helmberger (1988), Miranda \& Glauber (1993), Gardner e López (1996), Makki et al. (1996) e Lence \& Hayes (2000). O modelo desenvolvido para o mercado brasileiro de milho resulta em parte da adaptação dos modelos existentes e é original em parte. 


\section{Material e Métodos}

\subsection{Modelo econômico}

Este trabalho considera apenas produtos agrícolas armazenáveis com produção anual e a unidade de tempo considerada é o ano safra. As expectativas do modelo são racionais no sentido de Muth (1961) e endógenas ao modelo ${ }^{1}$. O mercado é aberto e o governo intervém através do PEP, instalando um diferencial de preços no mercado - um para o produtor (mínimo, $P^{M}$ ) e o preço de mercado de equilíbrio. O governo não forma estoques. No período de plantio, cada produtor decide a área que pretende plantar, maximizando o lucro esperado, dado por:

$$
E \Pi_{t}^{i}=\delta E_{t} P_{t+1^{*}} E_{t} Y_{t+1^{*}} A_{t}^{i}-C_{t}\left(A_{t}^{i}\right)
$$

onde $A_{t}^{i}$ é a área a ser plantada pelo produtor $i$ no período $t, E_{t} P_{t+1}$ é a sua expectativa em $t$ para o preço no período seguinte $(t+1), E_{t} Y_{t+1}$ é a sua expectativa quanto a produtividade no ano $t+1$ e $C_{t}$ é o custo total de produção, em função da área; $\delta$ é a taxa de desconto dada por $[1 /(1+r)]$ onde r é a taxa de juros. A condição de primeira ordem para maximização do lucro do produtor em relação à área a ser plantada é dada por:

$$
\frac{\partial E \prod_{t}^{i}}{\partial A_{t}^{i}}=\delta E_{t} P_{t+1} * E_{t} Y_{t+1}-c_{t}^{i}=0
$$

Em ambiente competitivo o produtor iguala o custo por hectare $\left(c_{t}^{i}\right)$ à receita marginal esperada por hectare $\left(\delta E_{t} P_{t+1^{*}} E_{t} Y_{t+1}\right)$. A área plantada é função do maior de dois valores: preço mínimo e preço de mercado esperado e atende à condição de equilíbrio dada em (2):

$$
\begin{aligned}
& A_{t}=A\left[\max \left(E_{t} P_{t+1}, P_{t+1}^{M}\right)\right] \\
& \partial A_{t} / \partial E_{t} P_{t+1}>0 ; \partial A_{t} / \partial P_{t+1}^{M}>0
\end{aligned}
$$

\footnotetext{
${ }^{1}$ Isto significa que a função do preço esperado não é conhecida $a$ priori e é determinada pelo modelo, de acordo com o estoque inicial de produto no ano safra. Justamente porque a função do preço esperado não é conhecida nem a função do estoque a ser formado, que o modelo não pode ser obtido por outra metodologia a não ser a programação dinâmica estocástica. As expectativas racionais neste modelo são prospectivas e não adaptativas.
} 
onde $A_{\mathrm{t}}$ é a área plantada no ano $t, E_{t}\left(P_{t+1}\right)$ é a expectativa dos produtores quanto ao preço para o ano safra seguinte e $P^{M}{ }_{t+1}$ é o preço mínimo anunciado no ano safra $t$ a vigorar no ano safra $t+1$. O prêmio ou subsídio $\left(\theta_{t}\right)$ a ser pago pelo governo por unidade de produto será dado por:

$$
\begin{aligned}
& P_{t}>P^{\mathrm{M}} \quad \Rightarrow \quad \theta_{t}=0 \\
& P_{t}<P^{\mathrm{M}} \quad \Rightarrow \quad \theta_{t}=\left(P^{\mathrm{M}}-P_{t}\right)
\end{aligned}
$$

O subsídio é concedido apenas ao produtor e para a produção colhida no ano safra. Assim, o subsídio total do ano $(\Theta \mathrm{t})$ é o produto do subsídio por unidade e da produção do ano. A produção que será colhida no ano safra (Ht) é o produto da área plantada no ano safra anterior e da produtividade obtida no ano (Yt):

$$
H_{t}=A_{t-1}{ }^{*} Y_{\mathrm{t}}
$$

A produtividade é uma variável exógena aleatória com distribuição normal, média $\mu$ e variância $\sigma^{2}\left(Y_{t} \approx \mathrm{N}\left(\mu, \sigma^{2}\right)\right)$ e sua variabilidade corresponde aos choques de oferta, provenientes de variações climáticas sobre a produtividade. $\mathrm{O}$ ano safra começa com uma disponibilidade inicial $S_{t}$ composta dos estoques finais privados do ano safra anterior $\left(I_{t-1}^{i}\right)$ e da nova produção $\left(H_{t}\right)$ :

$$
S_{\mathrm{t}}=I_{\mathrm{t}-1}+H_{\mathrm{t}}
$$

A função inversa da demanda para consumo é uma função negativamente inclinada dos preços correntes de mercado e de um choque aleatório $u_{t}$, que apresenta distribuição normal, média zero e variância $\sigma^{2}\left(u_{t} \approx \mathrm{N}\left(0, \sigma^{2}\right)\right)$ :

$$
\begin{aligned}
& P_{\mathrm{t}}=\mathrm{P}\left(D_{\mathrm{t}}, u_{\mathrm{t}}\right) \\
& \partial P_{\mathrm{t}} / \partial D_{\mathrm{t}}<0
\end{aligned}
$$

Admite-se que as funções de oferta de área e de demanda para consumo são as mesmas em todos os anos. O comércio internacional é incluído através de uma condição de arbitragem espacial entre o mercado interno e o externo: 


$$
\begin{aligned}
& P^{R M}{ }_{t}-\tau_{t}-P_{t} \geq 0 \quad M_{t} \geq 0 \\
& P^{R M}{ }_{t}-\tau_{t}-P_{t}<0 \quad M_{t}<0
\end{aligned}
$$

Onde $\tau_{\mathrm{t}}$ é o custo de transação no mercado internacional, considerado o mesmo tanto para a exportação quanto para a importação. A expressão (8) significa que, quando o preço no mercado externo ( $\mathrm{P}_{\mathrm{t}}^{\mathrm{RM}}$ ) é maior do que o preço no mercado interno $\left(\mathrm{P}_{\mathrm{t}}\right)$ mais o custo de Transação, o país exporta $(\mathrm{M}>0)$; quando ocorre o inverso, o país importa. O Brasil foi considerado pequeno no mercado internacional do milho e, assim, um tomador de preços. O volume de produto disponível será utilizado para consumo ou será armazenado e, quanto ao comércio internacional, parte da disponibilidade pode ser alocada para exportação $(\mathrm{M}>0)$ ou então o montante disponível aumenta pelo volume de importações $(M<0)$. Se a relação for de igualdade não há comércio exterior.

$$
S_{t}=D_{t}+I_{t}+M_{t}
$$

Substituindo (6) em (9):

$$
D_{t}=I_{t-1}+H_{t}-I_{t}-M_{t}
$$

O nível de estoque privado de equilíbrio que será formado segue a condição de arbitragem temporal:

$$
\begin{array}{ll}
\delta \mathrm{E}_{\mathrm{t}} P_{\mathrm{t}+1} \geq P_{\mathrm{t}}+\mathrm{k} & I_{\mathrm{t}} \geq 0 \\
\delta \mathrm{E}_{\mathrm{t}+1} P_{\mathrm{t}+1}<P_{\mathrm{t}}+\mathrm{k} & I_{\mathrm{t}}=0
\end{array}
$$

A relação (11) implica em que, se o preço esperado (a valor presente) for menor do que o preço corrente mais o custo de armazenamento, não se formam estoques $\left(I_{t}=0\right)$. A solução deste sistema de equações é o estoque de equilíbrio. Observe que o preço esperado (expectativa racional) para o período $t+1$ é função do estoque a ser formado no período $t$. Explicitamente o que se procura é o valor de $I_{t}$ que soluciona a seguinte expressão:

$$
E P_{t+1}\left(I_{t}+A_{t} * Y_{t+1}-I_{t+1}-M_{t+1}\right)-P_{t}\left(I_{t-1}+A_{t-1} * Y_{t}-I_{t}-M_{t}\right)-k=0
$$




\subsection{Procedimento e dados}

Este modelo de expectativas racionais não possui solução algébrica e deve ser resolvido através de métodos numéricos (Gustafson, 1958). A solução do modelo é uma função que relaciona o estoque $\left(I_{t}\right)$ ao volume de produto disponível $\left(S_{t}\right)$ e permite obter os valores de equilíbrio para todas as variáveis endógenas. Trata-se de um modelo de equilíbrio dinâmico, o qual caracteriza o comportamento de um mercado através de condições de arbitragem intertemporal, que são atingidas pela ação individual de inúmeros agentes maximizadores. Gustafon (1958) formulou o problema do armazenamento como um problema de otimização dinâmica, sob a teoria do controle. O estoque no tempo é a política ótima, que corresponde à solução do problema, de acordo com o Princípio de Bellman (Kennedy, 1986). Formulado nesta ótica, o problema pode ser solucionado através de métodos numéricos.

Nesta abordagem, o problema do armazenamento corresponde a um problema dinâmico de expectativas racionais, onde as variáveis estado e decisão são contínuas e pertencem a um conjunto convexo fechado não nulo, mas o tempo é discreto (Miranda \& Fackler, 2001). Se a função do preço de equilíbrio do mercado fosse conhecida, a expectativa racional ex ante do preço poderia ser computada integrando a partir da distribuição de probabilidade da produtividade $Y$ e do choque de demanda $u_{t}$. Adicionando esta equação às anteriores, o resultado seria um sistema de equações algébricas não lineares que seria determinado e, em princípio, com solução para todas as incógnitas.

Desde que se conheça a função do preço esperado, a solução não apresenta maior dificuldade. A distribuição contínua de probabilidade da variável aleatória é transformada em uma distribuição discreta ${ }^{2}$ o que permite o cálculo do preço esperado para qualquer disponibilidade inicial. O problema é que a função do preço esperado não é conhecida, mas pode ser aproximada através de polinômios Judd (1999). Este estudo aproxima a função do preço esperado através de um polinômio de quarta ordem, seguindo a sugestão de Wright \& Williams (1991).

A partir da produtividade média brasileira no período analisado e o

${ }^{2}$ Segundo a Quadratura de Gauss (Miranda \& Fackler, 2001) 
respectivo desvio padrão foi construída uma distribuição de freqüência discreta desta variável com 8 valores e respectivas probabilidades, assumindo distribuição normal. $\mathrm{O}$ mesmo procedimento foi adotado para os choques de demanda (6 valores), partindo dos resíduos da regressão de ajustamento da demanda para consumo. Estas são as duas variáveis estocásticas do modelo. Para as simulações, foram gerados 2.500 valores aleatórios de cada variável. Produtividade e choques de demanda foram considerados independentes. Estes valores foram gerados através do programa Matlab. Todos os demais cálculos foram realizados em planilha eletrônica. O algoritmo pode ser obtido entrando em contato com os autores. Os parâmetros utilizados no modelo são apresentados em anexo.

\section{Dados}

Foram estimadas funções de demanda para consumo e oferta de área plantada para milho no Brasil, obtidos os valores médios históricos, para o período de 1986 a 2000, do custo de armazenamento físico por tonelada, do preço médio do milho no mercado internacional representado pela Bolsa de Chicago, do custo médio de importação/exportação do produto tendo como referência uma distância média de 300 quilômetros até o porto. A taxa de juros utilizada foi de $12 \%$ ao ano. As áreas plantadas consideradas para estimar a função de oferta são do IBGE. O custo de armazenamento foi calculado a partir das tabelas de preços da CONAB para produto a granel. Os preços de mercado externo se referem às cotações para primeiro vencimento na Bolsa de Chicago. Os custos para exportar/importar foram obtidos junto a empresas do setor. O preço de mercado para o milho, usado para estimar a função de demanda tem como fonte a Fundação Getúlio Vargas. Todos os preços foram deflacionados pelo IGP-DI para março de 2001.

\section{Resultados e discussão}

A Figura 1 anexo apresenta a política ótima ou regra do armazenamento que relaciona, para cada disponibilidade inicial, o volume ótimo de estoque. Pelo fato de haver comércio com o mercado externo, a formação de estoques internamente só é economicamente viável para preços de equilíbrio entre a paridade de importação e de exportação. 
O estoque privado passa a existir a partir de uma disponibilidade de 35,1 milhões de toneladas e se torna estável a partir de 37 milhões que corresponde ao volume a partir do qual se torna viável exportar, dados os parâmetros do modelo.

Uma visão geral das análises que o modelo permite é considerar as médias de longo prazo das variáveis endógenas, obtidas por meio de simulações para um determinado período de tempo. Neste estudo o período foi de 10 anos começando no ano zero com uma determinada disponibilidade inicial. Segundo Wright \& Williams (1991) e Miranda \& Fackler (2001), as simulações devem partir de um ano com disponibilidade inicial acima ou abaixo da média para permitir avaliar de que forma um choque inicial positivo ou negativo é absorvido pelo sistema.

Figura 1 - Disponibilidade inicial e estoque de milho de equilíbrio, em milhões de toneladas.

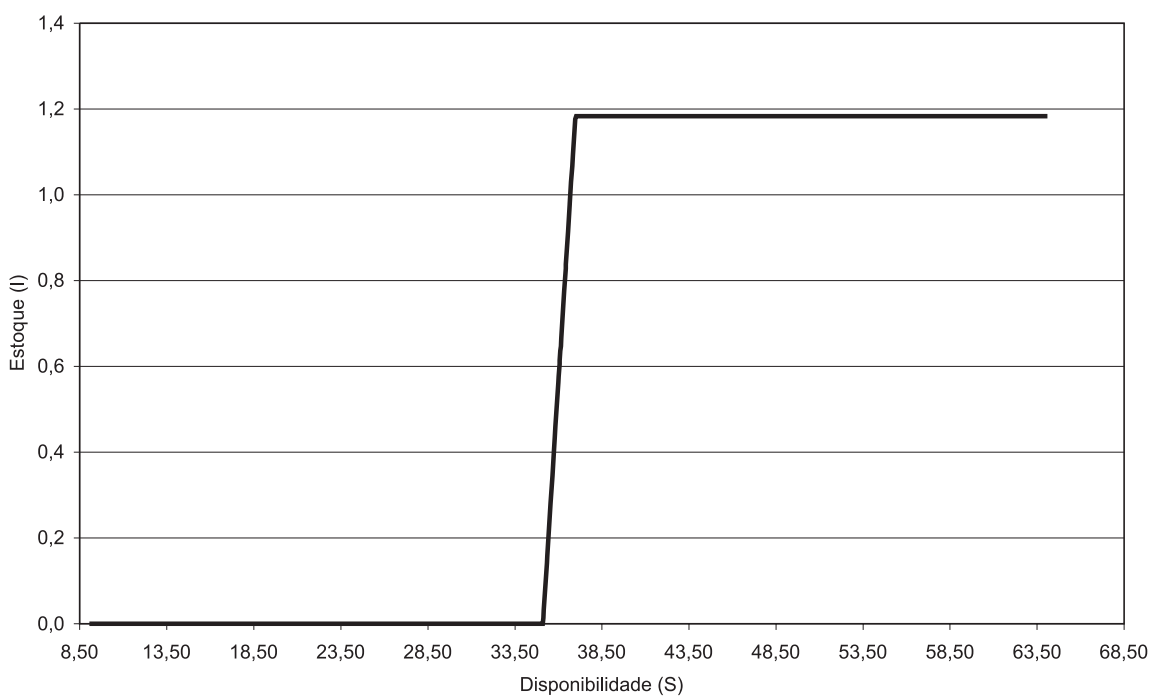

O importante é que, partindo de um período de excesso de oferta ou de escassez, o modelo deve convergir para a média de longo prazo. A opção de simulação foi para uma disponibilidade inicial acima da média, de 40 milhões de toneladas, resultado de um estoque anterior de 5 milhões de toneladas e nova produção de 35 milhões. Esta seqüência de 10 anos foi simulada 2.500 vezes para cada modelo e a média de cada 
ano é a média destes 2.500 valores. Este tipo de análise permite averiguar de que maneira o sistema absorve o excesso de oferta inicial. $\mathrm{O}$ ano zero representa a primeira resposta do mercado à abertura e à implantação da política. Uma vez aberto o mercado e definida a política, esta situação perdura para os anos seguintes. Na Tabela 1 são apresentados os valores médios de longo prazo das variáveis endógenas do modelo que representa o mercado brasileiro de milho a partir do final da década de 1990. As Tabelas 2 e 3, em anexo, apresentam dois resultados das 2.500 simulações que geraram as médias apresentadas na Tabela 1.

Tabela 1. Médias de longo prazo das variáveis endógenas, em mil toneladas, para o modelo de economia aberta com intervenção através de PEP.

\begin{tabular}{|c|c|c|c|c|c|c|c|c|c|c|}
\hline & $\begin{array}{c}\text { Estoque } \\
\text { Inicial } \\
\left(\mathrm{I}_{t-1}\right) \\
\end{array}$ & $\begin{array}{c}\text { Produção } \\
\left(\mathrm{H}_{\mathrm{t}}\right)\end{array}$ & $\begin{array}{c}\text { Impor- } \\
\text { tação } \\
\left(\mathrm{M}_{+}\right) \\
\end{array}$ & $\begin{array}{l}\text { Disponi- } \\
\text { bilidade }^{1} \\
\left(\mathrm{~S}_{+}\right)\end{array}$ & $\begin{array}{c}\text { Consumo } \\
\left(D_{t}\right)\end{array}$ & $\begin{array}{c}\text { Expor- } \\
\text { tação } \\
\left(\mathrm{M}_{+}\right) \\
\end{array}$ & $\begin{array}{c}\text { Estoque } \\
\text { Final } \\
\left(\mathrm{I}_{+}\right)\end{array}$ & $\begin{array}{c}\mathrm{P}_{\mathrm{t}} \\
(\mathrm{R} \$ / \mathrm{t})\end{array}$ & $(\mathrm{R} \$ / \mathrm{t})$ & $A_{t}$ \\
\hline 0 & $5.000,0$ & $35.000,0$ & - & $40.000,0$ & $35.793,3$ & $3.028,6$ & $1.178,2$ & 190,0 & 28,00 & $12.965,2$ \\
\hline 1 & $1.178,2$ & $30.965,2$ & 472,9 & $32.615,6$ & $31.950,3$ & 404,4 & 260,9 & 240,3 & 8,42 & $12.981,1$ \\
\hline 2 & 260,9 & $31.309,3$ & 601,8 & $32.169,5$ & $31.575,4$ & 369,8 & 224,3 & 245,3 & 7,25 & $12.981,9$ \\
\hline 3 & 224,3 & $31.204,4$ & 628,8 & $32.056,9$ & 31. & 391,1 & 226,4 & 247,0 & 7,09 & $12.981,8$ \\
\hline 4 & 226,4 & $31.213,4$ & 564,7 & $32.003,6$ & 31 & 344,2 & 202,7 & 246,8 & 6,58 & 12.982 \\
\hline 5 & 202,7 & $31.089,2$ & 629,2 & $31.920,5$ & $31.391,9$ & 332,0 & 196,7 & 247,7 & 6,63 & $12.982,3$ \\
\hline 6 & 196,7 & $31.095,0$ & 659,0 & $31.951,3$ & $31.404,6$ & 336,2 & 210,4 & 247,5 & 6,72 & $12.982,0$ \\
\hline 7 & 210,4 & $30.941,9$ & 736,5 & $31.888,6$ & $31.332,5$ & 348,2 & 207,9 & 248,4 & 6,61 & $12.982,1$ \\
\hline 8 & 207,9 & $31.052,0$ & 671,6 & $31.932,3$ & $31.360,0$ & 355,5 & 216,8 & 248,1 & 6,88 & $12.981,9$ \\
\hline 9 & 216,8 & $31.200,3$ & 651,6 & $32.068,2$ & $31.454,0$ & 388,0 & 226,1 & 246,8 & 7,11 & $12.981,8$ \\
\hline 10 & 226,1 & $31.266,3$ & 636,2 & $32.128,6$ & $31.522,7$ & 385,3 & 220,6 & 245,9 & 7,23 & $12.981,9$ \\
\hline
\end{tabular}

${ }^{1}$ Inclui os choques de demanda

A leitura dos resultados deve ser feita em linha, facilitando a compreensão dos mesmos. A cada ano, dada uma disponibilidade inicial, o preço do ano, o volume que será consumido, o volume a ser esto- 
cado e a área plantada no ano, para ser colhida no ano seguinte, são os valores de equilíbrio para aquele ano. A política de subsídio afeta, inicialmente, a área plantada, que será sempre função do maior valor: preço esperado para o ano seguinte ou o preço mínimo. Assim, mesmo quando o estoque é relativamente alto (reduzindo o preço esperado) a área plantada não reduz se o preço mínimo for superior ao esperado.

Figura 2 - Índice do consumo médio de longo prazo de milho $\left(D_{t}\right)$, para o modelo de economia aberta com intervenção via PEP.

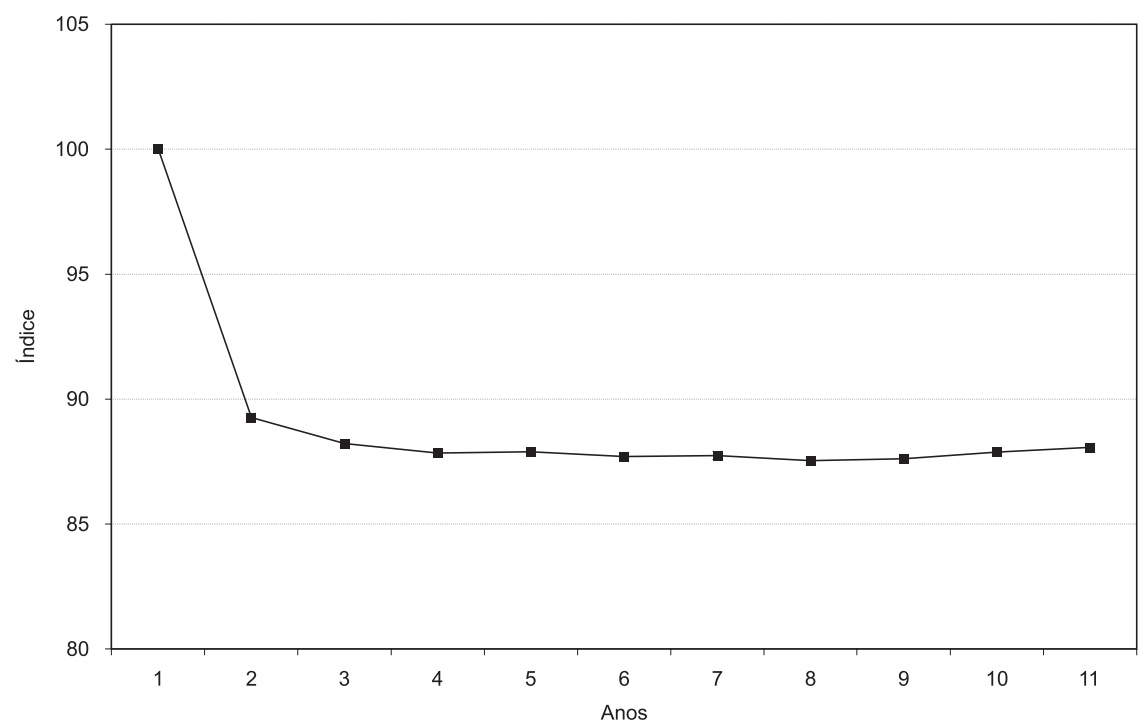

Não reduzindo a área, há uma tendência para haver uma maior disponibilidade de produto internamente, o que beneficia os consumidores. Os valores médios de longo prazo do consumo para o período simulado são apresentados na Figura 2, na forma de índice, ou seja, tendo o valor no ano zero como base 100 e os valores dos demais anos, proporcionais a este valor inicial.

A disponibilidade inicial acima da média é absorvida no ano safra seguinte através de exportação. O consumo interno se mantém estável nos anos seguintes porque excessos são canalizados para exportação e estoque interno, e períodos de escassez são compensados por compras externas. 
Os preços tendem a se estabilizar em torno da média de longo prazo, lembrando que estas médias são resultado de diversas combinações de choques de oferta e demanda internos, mantidos constantes os valores para preço externo e preço mínimo (Figura 3). O estoque ao longo do tempo para a média de longo prazo reduz-se para $20 \%$ do volume inicial. O mercado externo passa a receber e fornecer o volume de produto necessário para atender o consumo interno. Nos anos em que o preço de equilíbrio do mercado é inferior ao preço mínimo, o governo realiza leilões de PEP. Considerando que o ambiente é competitivo, o prêmio deve equivaler à diferença entre o preço de equilíbrio e o preço mínimo. Os valores médios deste subsídio também são apresentados na tabela. O gasto médio do governo ao longo do tempo pode ser visualizado na Figura 4.

Da forma apresentada no estudo, o mercado externo impõe uma faixa de preços para o mercado brasileiro. O efeito é semelhante ao pretendido por uma política de estoques reguladores, mas sem que o governo forme estoques. Os resultados mostram que o estoque formado pela iniciativa privada também ocorre dentro desta faixa de preços. $\mathrm{Na}$ prática, esta faixa muda de posição freqüentemente, acompanhando as oscilações do mercado internacional. Os preços internos devem variar dentro da faixa imposta pelos preços de paridade com o exterior, mas a faixa muda de posição o que torna impossível, a médio e longo prazo, estabilizar os preços internos apenas garantir uma faixa de variação que não seria possível com economia fechada.

Os resultados analíticos do modelo estão condicionados aos parâmetros estabelecidos, entre eles a relação entre o preço mínimo e de paridade de exportação e importação, que são médias históricas do período 1986 a 2000. O preço mínimo, nestas circunstâncias, é maior do que o preço de paridade de exportação e inferior ao de importação. Nestas circunstâncias, a área plantada tende a se manter em nível ou acima do valor de equilíbrio relativo ao preço mínimo. O gasto do governo cresce quanto maior a produção, o que indica que, quanto maior o preço mínimo, maior disponibilidade interna e, dependendo do valor relativo do subsídio e da função de oferta de área, o país poderia se tornar exportador. Diversas simulações são possíveis através destes modelos, com diferentes preços mínimos, preços externos, tornando o país importante no mercado externo (oferta e/ou demanda externas não perfeitamente inelásticas), entre outros. 
Figura 3 - Índice do preço médio de longo prazo de milho $\left(P_{t}\right)$, para o modelo de economia aberta com intervenção via PEP.

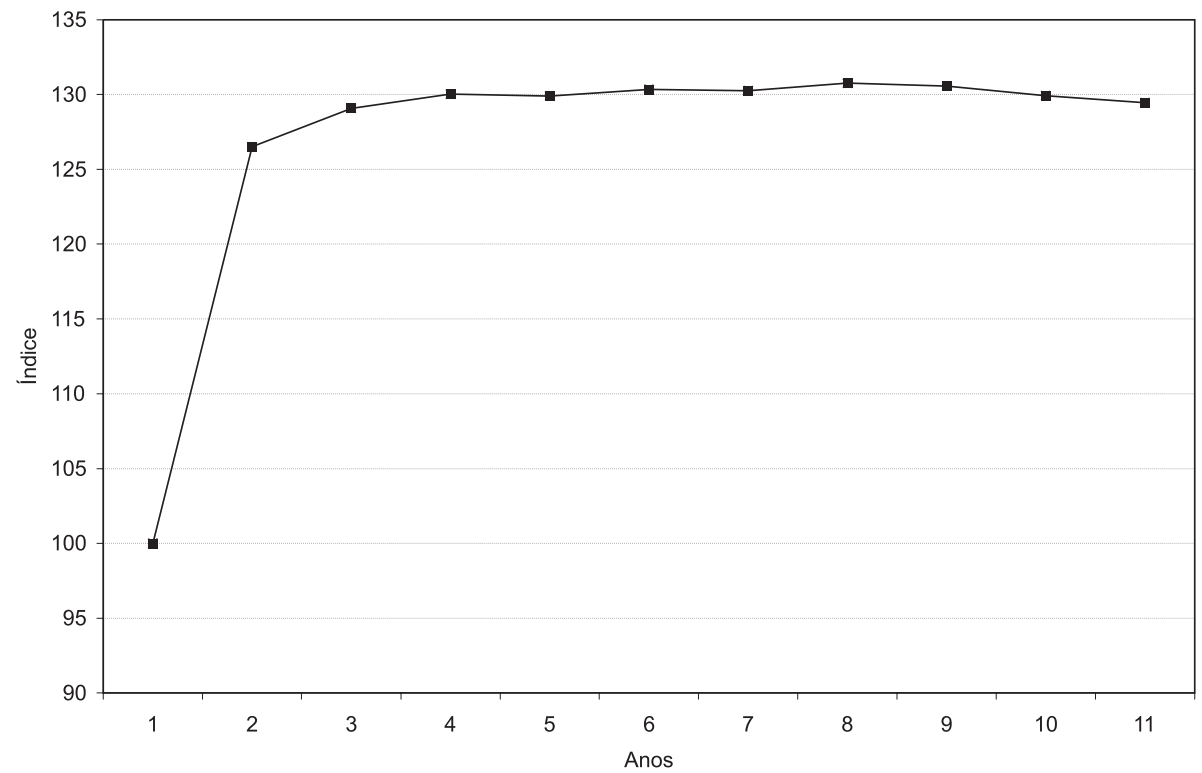

Figura 4 - Gastos do governo com PEP para o modelo de economia aberta com intervenção

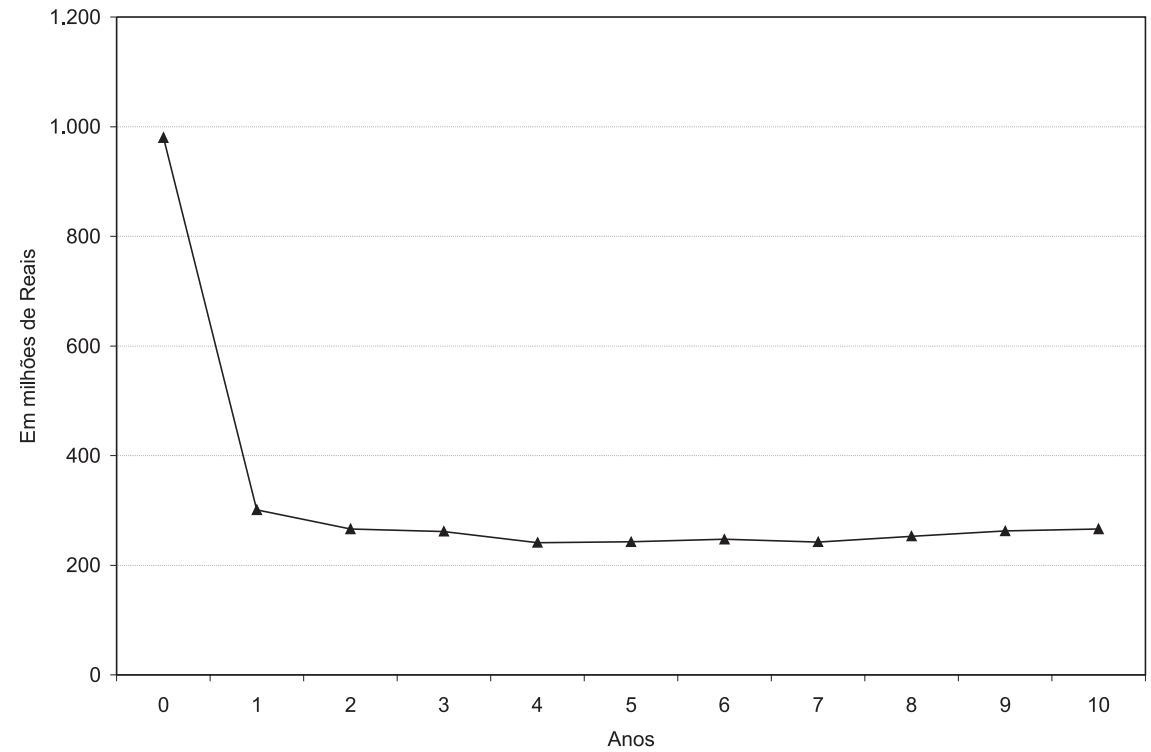

RER, Rio de Janeiro, vol. 44, no 04, p. 751-771, out/dez 2006 - Impressa em dezembro 2006 
Os modelos econômicos desenvolvidos neste estudo podem ser utilizados para quaisquer produtos agrícolas armazenáveis com produção anual, tais como arroz, trigo e algodão. Em princípio qualquer política de preços vinculada a estes mercados pode ser incorporada aos modelos permitindo avaliar seus impactos sobre o mercado como um todo. Destaca-se, novamente, que o modelo é prospectivo e não retrospectivo - pode ser usado para previsões do equilíbrio do mercado e da necessidade ou não de intervenção do governo e em qual volume de recursos. Por isso o modelo não foi comparado a nenhuma seqüência de valores do passado porque os parâmetros que são mantidos constantes no modelo não se mantiveram fixos ao longo do tempo (passado), tais como os preços internacionais e preço mínimo. A maior utilidade deste estudo é a possibilidade de modelar o mercado a cada momento (alterando os parâmetros) e estimar os equilíbrios de mercado futuros.

\section{Conclusão}

A abertura ao comércio exterior tem forte influência sobre o equilíbrio dinâmico do mercado brasileiro de milho, tanto sobre os preços internos quanto na formação de estoques. Com mercado aberto, um país pequeno no mercado internacional, tem sua formação de estoques delegada ao resto do mundo e o país dependerá das compras externas para compensar os choques de oferta e demanda internos. Os resultados sugerem que, quanto maior o preço mínimo, maior a oferta interna, o que pode tornar o país um crescente exportador. Como o PEP é um subsídio de preço ao produtor, sua influência se dá sobre a área plantada, que será maior quanto maior o preço mínimo. Quanto mais excedente de produto houver no mercado, maior o volume a ser exportado. Atualmente o Brasil é um pequeno exportador de milho, mas dependendo do valor do preço mínimo e dos preços externos, o país pode passar a exportar volumes mais expressivos. Tal política poderia receber críticas internacionais, em função dos acordos comerciais em andamento.

Um preço mínimo inferior ao preço de paridade de exportação torna a política inócua, pois os preços esperados serão sempre superiores ao preço mínimo. A determinação dos níveis de preços mínimos para os produtos amparados pela Política de Garantia de Preços Mínimos com 
mercados abertos exige do governo estudos para diferentes cenários. Uma das muitas possibilidades que os modelos desenvolvidos neste estudo permite é incluir uma restrição orçamentária ao governo para a execução da política para cada produto. Sob esta restrição é possível estimar os valores de equilíbrio das variáveis endógenas do modelo. Estas e outras análises podem ser feitas buscando os novos equilíbrios para mudanças nos parâmetros dos modelos tais como o custo de armazenamento e a taxa de juros. Os resultados analíticos mostram a consistência teórica dos modelos e abrem um amplo leque de situações em que esta modelagem pode ser utilizada para estimar as respostas do mercado a estas mudanças.

\section{Referências bibliográficas}

BARROS, G.S.A.C.; GUIMARÃES, V.D.A. Análise da eficácia da política de preços para arroz e milho por meio de um modelo econômico de expectativas racionais. Revista de Economia e Sociologia Rural, v.36, n.4, p.113-133, 1998.

COMPANHIA NACIONAL DE ABASTECIMENTO. Regulamento para oferta de prêmio para escoamento de produto - PEP. http://conab. gov.br/comercializacao/regulamentopep.doc (06 Jun. 2000a)

GARDNER, B. Optimal stockpiling of grain. Lexington: Lexington Books, 1979. 175p.

GARDNER, B.; LÓPEZ, R. Interest-rate subsidies in price stabilization. American Journal of Agricultural Economics, v.78, n.3, p.508-516, 1996.

GLAUBER, J.; HELMBERGER, P.; MIRANDA, M. Four approaches to commodity market stabilization: a comparative analysis. American Journal of Agricultural Economics, v.71, n.2, p.326-337, 1989.

GUSTAFSON, R.L. Carryover levels for grain: a method for determining amounts that are optimal under specified conditions. Washington: USDA, 1958. 92p. (Technical Bulletin, 1178)

JUDD, K.L. Numerical methods in economics. Cambridge: The MIT Press, 1999. 633p. 
KENNEDY, J.O.S. Dynamic programming: applications to agriculture and natural resources. London: Elsevier Applied Science, 1986. 341p.

LENCE, S.H.; HAYES, D.J. U.S. farm policy and the variability of commodity prices and farm revenues. Ames: Iowa State University, 2000. 36p. (Working Paper, 00-WP 239)

LIMA, S.M.A; BARROS, G.S.A.C. Eficácia da política de preços mínimos nos anos 80 e 90: o caso do milho no Brasil. Revista Brasileira de Economia, v.50, n.2, p.161-178, 1996.

LOWRY, M.; GLAUBER, J.; MIRANDA, M.; HELMBERGER, P. Pricing and storage of field crops: a quarterly model applied to soybeans. American Journal of Agricultural Economics, v.69, n.4, p.740-749, Nov.1987.

MAKKI, S.S.; TWEETEN, L.G.; MIRANDA, M.J. Wheat storage and trade in an efficient global market. American Journal of Agricultural Economics, v.78, n.4, p.879-890, Nov.1996.

MASSEL, B.F. Price stabilization and welfare. Quarterly Journal of Economics, v.83, n.2, p.284-298, 1969.

MIRANDA, M.J.; FACKLER, P.L. Applied computational economics and finance. http://www4.ncsu.edu/ pfackler/compecon/compecon.pdf (12 Mai. 2001).

MIRANDA, M.J.; GLAUBER, J.W. Estimation of dynamic nonlinear rational expectations models for primary commodity markets with private and government stockholding. Review of Economics and Statistics, v.75, n.3, p.463-470, Aug.1993.

MIRANDA, M.J.; HELMBERGER, P.B. The effects of commodity price stabilization programs. American Economic Review, v.78, n.1, p.4657, Mar.1988.

MUTH, J.F. Rational expectations and the theory of price movements. Econometrica, v.29, n.2, p.315-335, Apr.1961.

REUTLINGER, S. A simulation model for evaluating worldwide buffer stocks of wheat. American Journal of Agricultural Economics, v.58, n.1, p.1-12, Feb.1976. 
OI, W.Y. The desirability of price instability under perfect competition. Econometrica, v.29, n.2, p.58-62, Apr. 1961.

TURNOVSKY, S.J. Price expectations and the welfare grains from price stabilization. American Journal of Agricultural Economics, v.56, n.4, p.706-716, Nov.1974.

WAUGH, F.V. Does the consumer gain from price instability? Quarterly Journal of Economics, v.58, n.2, p.602-614, Aug, 1944.

WRIGHT, B.R.; WILLIAMS, J.C. The welfare effects of the introduction of storage. Quarterly Journal of Economics, v.99, n.1, p.169-182, Feb.1984.

WRIGHT, B.R.; WILLIAMS, J.C. Storage and commodity markets. New York: Cambridge University Press, 1991. 502p. 


\section{Anexo}

Tabela 1 - Dados e parâmetros dos modelos

Parâmetros

Termo constante da função inversa da demanda para consumo

Coeficiente do preço

Coeficiente da renda

Renda anual média

Termo constante da função de oferta de área

Coeficiente angular da função de oferta de área

Produtividade média (Kg/ha)

Desvio padrão da produtividade $(\mathrm{Kg} / \mathrm{ha})$

Desvio padrão dos choques de demanda (Em mil toneladas)

Taxa anual de juros (\%)

Custo unitário anual de armazenamento (R \$/tonelada)

Preço mínimo (R\$/tonelada)

Preço importação (R $\$$ /tonelada)

Preço exportação (R \$/tonelada)

Custo de exportação/importação (R\$/tonelada)
Valor

401,8700906

$-0,0131006$

257,0432

$7,229,31$

$12.554,99766$

0,718457

2.400

367

$1.794,908856$

$12 \%$

25,17

218,00

300,00

190,00

110,00 




RER, Rio de Janeiro, vol. 44, no 04, p. 751-771, out/dez 2006 - Impressa em dezembro 2006 


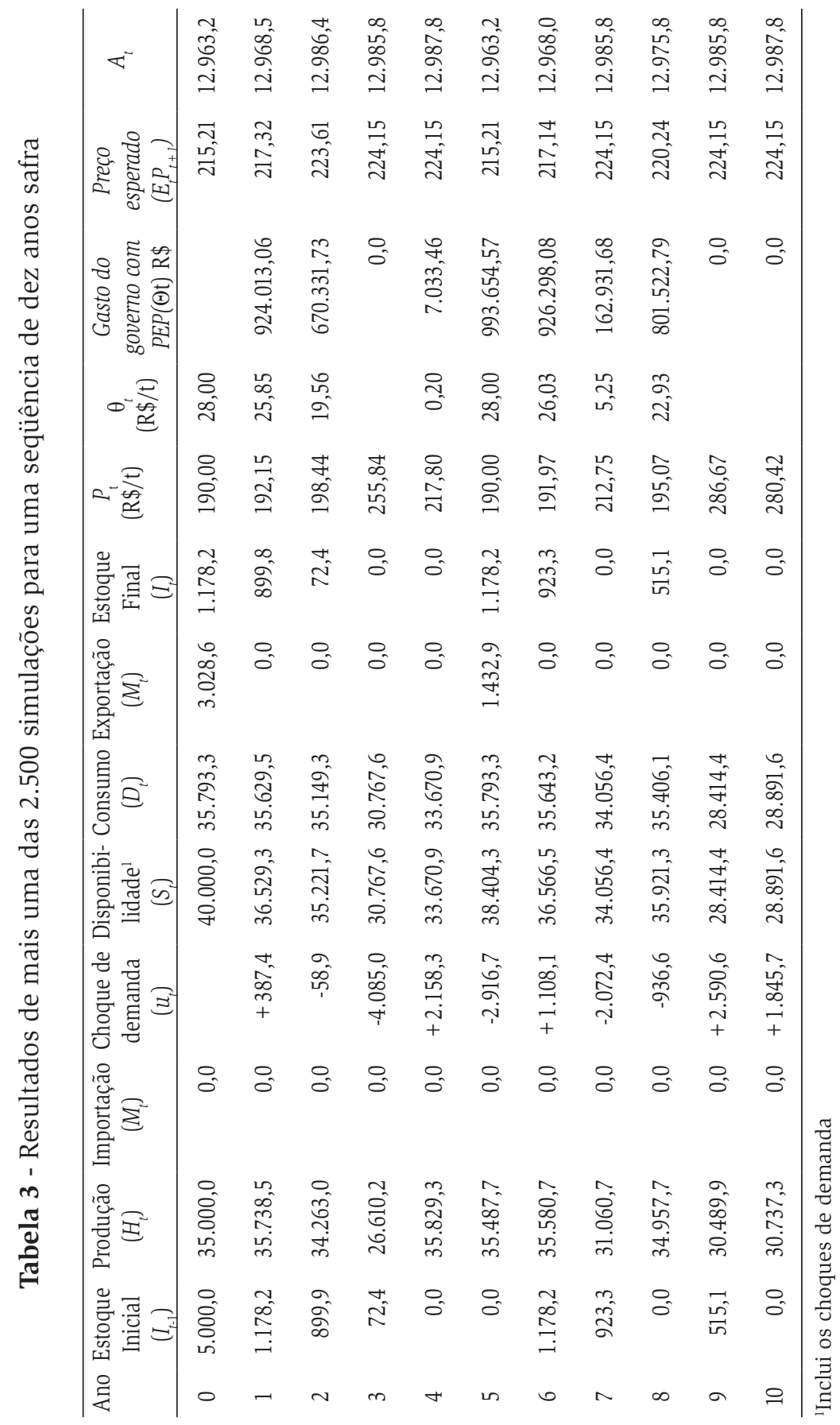


Tanto a Tabela 2 quanto a Tabela 3 devem ser lidas em linha, que representa um ano safra possível para o mercado de milho, como enfatizado no texto, dados os parâmetros utilizados nesta modelagem (apresentados na Tabela 1 deste anexo). Nestas tabelas são apresentadas duas das 2.500 simulações feitas neste estudo e mostram como (e quantificam) o mercado se ajustaria em cada situação.

Tomando a Tabela 1 a leitura é a seguinte. $\mathrm{O}$ ano 1 começa com o estoque inicial formado no ano zero $\left(I_{t-1}\right)$ de 1.178,2 mil toneladas de milho. A área plantada no ano zero $\left(A_{t-1}\right)$ foi de 12.963,2 mil hectares cuja produção é colhida no ano 1 , e foi de $32.369,0$ mil toneladas $\left(H_{t}\right)$. Um dos parâmetros é a produtividade média de 2,4 toneladas por hectare o que daria uma produção no ano 1 de 31.111,6 mil toneladas, no entanto, a produção foi maior o que implica um choque positivo de oferta neste ano - a produtividade média, aleatória e estocástica foi de $2.492 \mathrm{~kg} / \mathrm{ha}$ - uma das variáveis exógenas ao modelo pois depende das condições climáticas. Além disso, neste ano ocorre um choque de demanda $\left(u_{t}\right)$, positivo, em 1.739,6 mil toneladas. De acordo com o modelo, soma-se à produção o estoque inicial e deduz-se o choque de demanda resultando na disponibilidade total do ano $\left(S_{t}\right)$. A partir deste total o modelo encontra a solução de equilíbrio, que é endógena, simultaneamente para as seguintes variáveis: o preço de equilíbrio de mercado $\left(P_{\mathrm{t}}\right)$, a quantidade demandada internamente $\left(D_{t}\right)$, se haverá ou não importação ou exportação, qual o preço esperado para o ano safra seguinte $\left(E_{t} P_{t+1}\right)$ e conseqüentemente, qual o estoque que será formado no ano $t\left(I_{t}\right)$ e a área que será plantada $\left(A_{t}\right)$. Dado o equilíbrio, calcula-se se o PEP será realizado, o prêmio a ser pago e o gasto total do governo. Como no ano 1 o preço de equilíbrio de mercado ficou acima do preço mínimo, não haverá PEP. A mesma leitura se repete em seqüência para os anos seguintes. Em resumo o modelo permite antever, a partir de um determinado estoque inicial e os parâmetros mencionados, quais serão os valores de equilíbrio do mercado de milho em qualquer situação.

Recebido em junho de 2001 e revisto em agosto de 2006. 